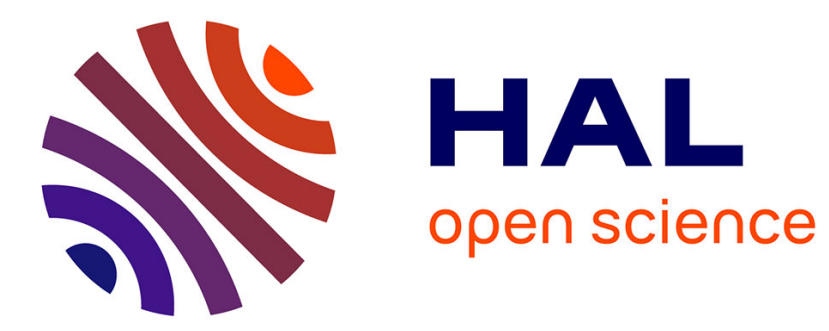

\title{
The analysis of convergence in ecological indicators : an application to the Mediterranean fisheries
}

\author{
M. Grazia Pennino, Jose Maria Bellido, David Conesa, Marta Coll, Emili
}

Tortosa-Ausina

\section{To cite this version:}

M. Grazia Pennino, Jose Maria Bellido, David Conesa, Marta Coll, Emili Tortosa-Ausina. The analysis of convergence in ecological indicators: an application to the Mediterranean fisheries. Ecological Indicators, 2017, 78, pp.449-457. 10.1016/j.ecolind.2017.03.041 . hal-01928496

\section{HAL Id: hal-01928496 \\ https://hal.science/hal-01928496}

Submitted on 7 Jan 2019

HAL is a multi-disciplinary open access archive for the deposit and dissemination of scientific research documents, whether they are published or not. The documents may come from teaching and research institutions in France or abroad, or from public or private research centers.
L'archive ouverte pluridisciplinaire HAL, est destinée au dépôt et à la diffusion de documents scientifiques de niveau recherche, publiés ou non, émanant des établissements d'enseignement et de recherche français ou étrangers, des laboratoires publics ou privés. 


\title{
The analysis of convergence in ecological indicators: An application to the Mediterranean fisheries
}

\author{
M. Grazia Pennino ${ }^{a, *}$, Jose Maria Bellido ${ }^{a}$, David Conesa ${ }^{b}$, Marta Coll ${ }^{c, d}$, \\ Emili Tortosa-Ausina e \\ a Instituto Espã̃ol de Oceanografía, Centro Oceanográfico de Murcia, Murcia, C/Varadero 1, San Pedro del Pinatar, 30740, Murcia, Spain \\ ${ }^{b}$ Departament d'Estadística i Investigació Operativa, Universitat de València, C/Dr. Moliner 50, Burjassot, 46100, Valencia, Spain \\ c Institut de Recherchepour le Développement, UMR MARBEC\& LMI ICEMASA,University of Cape Town, Private Bag X3, Rondebosch, Cape Town 7701, \\ South Africa \\ d Institut de Ciències del Mar (ICM-CSIC), Barcelona, Spain \\ e Department d'Economia, Universitat Jaumel, Campus del Riu Sec.,12080, Castelló de la Plana, Spain
}

\begin{abstract}
$a b s t r a c t$
Ecological indicators are increasingly used to examine the evolution of natural ecosystems and the impacts of human activities. Assessing their trends to develop comparative analyses is essential. We introduce the analysis of convergence, a novel approach to evaluate the dynamic and trends of ecological indicators and predict their behavior in the long-term. Specifically, we use a non-parametric estimation of Gaussian kernel density functions and transition probability matrix integrated in the R software. We validate the performance of our methodology through a practical application to three different ecological indicators to study whether Mediterranean countries converge towards similar fisheries practices. We focus on how distributions evolve over time for the Marine Trophic Index, the Fishing in Balance Index and the Expansion Factor during 1950-2010. Results show that Mediterranean countries persist in their fishery behaviors throughout the time series, although a tendency towards similar negative effects on the ecosystem is apparent in the long-term. This methodology can be easily reproduced with different indicators and/or ecosystems in order to analyze ecosystem dynamics.
\end{abstract}

\section{Introduction}

Ecological indicators are used in many ecological studies to examine the evolution of natural ecosystems and impacts of human activities. Comparing their trajectories and their behavior to develop comparative analyses is fundamental (Dale and Beyeler, 2001; Shin and Shannon, 2010).

An important topic is whether indicators are converging to the same behavior, thus highlighting that an ecosystem is moving towards a similar environmental status, for which we need to compare the indicators trends over time and predict the tendencies of the indicators in the long-term. Here, we present a novel methodology adapted from previously contributions in the field of Economics (Barro and Sala-i-Martin, 1992; Quah, 1993a; Quah,

* Corresponding author at: Instituto Español de Oceanografía, Centro Oceanográfico de Murcia, Murcia, Spain.

E-mail address: graziapennino@yahoo.it (M.G. Pennino). 1993b) and its first application to Ecology research. Opposite to the previous contributions (Barro and Sala-i-Martin, 1992) that based the analysis only in the mean and standard deviation of the indicators, our approach deals with the entire distribution, allowing us to give a more detailed vision of their behavior. Specifically, the analytical strategy we adopt involves three steps: (1) the evaluation of the external shape of the distribution of the indicators of interest; (2) the assessment of convergence or/and divergence of indicator patterns; and (3) the prediction in the long-term of the indicators' trends.

Ecological indicators are used to estimate the condition of the marine ecosystems to provide an early warning signal of changes in the exploitation of fishing resources, or to diagnose the cause of an environmental problem (Dale and Beyeler, 2001; Niemi and McDonald, 2004; Mitsch et al., 2005; Turnhout et al., 2007). They are able to quantify the magnitude of an ecological response to such an exposure and, they additionally provide a simple and efficient method for examining the ecosystem structure and function (Dale and Beyeler, 2001; Fulton et al., 2005; Cury et al., 2005). In this 
study, we use the analysis of convergence to investigate whether Mediterranean countries tend to converge in three ecological indicators calculated to characterize the impact of fishing in this basin: the Marine Trophic Index (Pauly and Watson, 2005), the Fishing in Balance index (Pauly et al., 2000; Christensen, 2000) and the Expansion factor (Kleisner et al., 2014). We calculate these three indicators per country and analyze, using the proposed distribution dynamics model, whether Mediterranean countries evolve to better or worse fishing practices and, consequently, we can forecast their impact based on those long-term tendencies.

This example takes into account the dynamic nature of ecosystems, especially when subjected to an industry, such as fishing, which is continuously undergoing rapid changes. Countries can differ on how they adjust to shifts in the fishery industry (new technologies, market prices and national laws), either in their speed of adaptation or in their degree of preparation for such shifts.

Nowadays it is widely accepted that a continuous failure (or lack) of fishing management is one of the most important factors both of the decreasing trend in world catches (Pauly and Zeller, 2016) and the higher impact of fisheries on the marine ecosystems (Hollingworth et al., 2000; Worm et al., 2006; Akpalu, 2009; Doyen et al., 2012 Worm and Branch, 2012). Therefore, the United Nations Food and Agriculture Organization (FAO) has called for the application of an Ecosystem Approach to Fisheries Management (EAFM), which aims to a sustainable exploitation of commercial fisheries (Pikitch et al., 2004; Cotter et al., 2009). A number of different methods and indicators for evaluating fisheries interactions in the ecosystem are now available (e.g.http://www.ebmtools.org). However, many of these methods are unsuitable for data-poor situations because they require detailed information that is generally difficult to achieve (Rosenberg et al., 2014).

The Mediterranean basin is a complex region that includes many different ecosystems characterized by a high level of marine biodiversity (Coll et al., 2010). The Mediterranean is at the crossroads between three continents, Asia, Africa and Europe, with very different cultural backgrounds, forms of governments and levels of development (Gonzalez-Riancho et al., 2009). Mediterranean fisheries are highly diverse and geographically varied, not only because of the existence of different marine environments, but also because of different socio-economic situations, and fisheries status (Colloca et al., 2013). The heterogeneity between countries can be investigated by the study of the behavior of the fishery exploitation in the different Mediterranean countries. Our hypothesis is that overfishing in developed countries could have generated negative effects/symptoms in the ecosystem that could be identified, prevented and cushioned in developing countries before they appear or are very high, thus preventing overexploitation of marine resources.

\section{The analysisof convergence}

\subsection{Nonparametric estimation of the univariate density functions}

The first step to evaluate how the entire distribution of a particular indicator evolves over time is to estimate non-parametrically their corresponding density functions for each sample year, or groups of years. The implications of this method for the analysis of dynamics are as follows: if the probability mass of a given indicator tends to be more markedly concentrated around a certain value, convergence for such an indicator is achieved. This outcome would imply that the behavior of the different countries tends to become gradually more similar in terms of the indicators being used. On the contrary, the opposite outcome (divergence) would be achieved if the probability mass was increasingly spread across a wider range, implying greater heterogeneity in the behavior of countries.
Different methods are available to estimate the density function of an indicator (Tortosa-Ausina, 2002). Here we propose the use of kernel smoothing. This technique is one of the most widely used in many situations, its properties are easily understood, and its discussion make it easier to deal with other methods (such as the naive estimator, the orthogonal series estimator, or the penalized maximum likelihood estimator) (Silverman, 1986; Scott, 1992).

This type of visual analysis (since we focus on how the shape of the distributions evolves) provides aflexible way to identify the real structure of the data without imposing any parametric model. Consequently, the use of these techniques makes it possible to reveal certain data structures such as, for example, a bimodal structure (which is impossible to uncover through a parametric unimodal model).

The kernel smoothing consists primarily of estimating the following density function for any indicator of interest:

$\hat{f}(x)=\frac{1}{S h}{ }_{s=1}^{s} K \frac{x-E i_{s}}{h}$,

where Sis the number of countries being analyzed, $\mathrm{Ei}_{\mathrm{s}}$ is the specific indicator, $\mathrm{K}$ is a kernel function and $\mathrm{h}$ is the bandwidth, window width or smoothing parameter.

There are multiple options for the kernel selection, including, among others, the Epanechnikov, triangular, Gaussian or rectangular methods. In our case, and based on the easiness of computation, we use the Gaussian kernel, which univariate expression is:

$K(t)=\frac{1}{\overline{2}} e^{-\frac{1}{2} t^{2}}$

After incorporating this kernel, Eq. (1) becomes:

$\hat{f}(x)=\frac{1}{S h}{ }_{s=1}^{S} \frac{1}{\overline{2}} e^{-\frac{1}{2} \frac{\left(x-E i_{s}\right)}{h}}$.

Whereas kernel selection determines the form of the bumps when the smoothing parameter $\mathrm{h}$ influences it differently, by determining the width of such bumps. However, bandwidth selection is far more important than kernel selection.

In this regard, the performance of the plug-in bandwidth proposed by Sheather and Jones (1991), based on the second generation method solve-the-equation plug-in-approach, is superior, in terms of a better balance between bias and variance, to the first generation methods (as shown by Jones et al., 1996). It is available through several statistical software packages such as $R(R$ Development Core Team, 2016). In the particular case of $R$, it is included in the "KernSmooth" package, by Matt Wand (Wand, 2015), via the "dpik" (direct plug-in) function.

\subsection{Intra-distribution mobility}

Nonparametric estimation of the univariate density functions provides information on the shape of the densities but conceals some dynamic patterns. In particular, it can be argued that the evolution of the densities might not offer a clear pattern either towards convergence or divergence while significant intra-distribution movements were taking place simultaneously. In other words, although the external shape of the density function might remain unaffected over time, changes in countries' relative positions, intradistribution mobility or churning could be taking place.

In order to overcome such shortcomings, a law of motion of the cross-section distribution is required; i.e.dynamics can be modeled with more precision. Finding out such a law and, therefore, drawing conclusions on the dynamics of the cross-section distribution of a given indicator, requires modeling the stochastic process that takes 
values that are probability measures associated to the cross-section distribution of the ecological indicator of interest at time $t$.

Bearing this in mind, in this second stage of the model, our aim is to build a formal statistical structure which captures the stated phenomena of intra-distribution mobility and, as we show later on, long-run behavior. However, the standard analysis does not provide suitable instruments for modeling the sequence of the distributions' dynamics, and for this reason we consider Markov Processes Theory in order to establish a duality through which to approach the problem. Specifically, in the same way that transition probability functions describe the dynamics of a scalar process, stochastic kernels describe the dynamics or law of motion of a sequence of distributions (Geweke et al., 1986; Quah, 1997).

Let $-\mathrm{t}$ be the probability measure associated to the distribution of each ecological indicator $F_{t}$ at time $t$, then the stochastic kernel describes the evolution from $-t$ to $-t+1$. Hence, if $M_{t}$ is a representation from 0 to 1 of the evolution from $-t$ to $-t+1$ for a specific ecological indicator, and assuming $M_{t}$ time-invariant, we have:

$$
\mathrm{t}+1=\mathrm{M}_{\mathrm{t}} \cdot \mathrm{t},
$$

where $M_{t}$ is a representation of the stochastic kernel with information on how to transit from a probability measure - $t$ (associated to the cross-section distribution $F_{t}$ ) to another one $-t+1$ (associated to $\left.F_{t+1}\right) .{ }^{1}$ This implies that the stochastic kernel conveys information on how the relative positions of the indicators of interest (which correspond to different countries) vary over time, which is equivalent to partly knowing the dynamics we attempt to model. Therefore, estimation of $\mathrm{M}$ from the available data allows empirically quantifying distribution dynamics.

Additionally, considering Eq. (4) and iterating we have that ${ }^{-t+s}=(M \cdot M \cdot \ldots \cdot M) \times{ }^{-} t$, an expression that, when $s \rightarrow \infty$, allows the ergodic distribution to be characterized. The ergodic distribution should not be considered exactly as a forecast for the future, as future realizations of the variables could be influenced in many ways. This concept should be more properly considered as a characterization of past years' tendencies, i.e. how will the future distribution of the variable of interest look like under current trends.

\subsection{Long-run tendencies: ergodic distribution}

Stochastic kernel distributions provide some further insights into the dynamics of a particular studied system, by identifying changes in the studied indicator trends. Some components of the dynamics, however, are still unsolved, namely the long-run behavior, or ergodic distributions, which we can do using this approach because we attempt to model the full dynamics of the distributions.

In order to compute the ergodic distribution and characterize long-run behavior, an indicator space has to be discretized. In such acase, measures $-\mathrm{t}$ are probability vectors and the stochastic kernel $\mathrm{M}$ becomes a transition probability matrix $\mathrm{Q}$. Hence, $\mathrm{M}$ and $\mathrm{Q}$ both refer to the stochastic kernel, but in the continuous and discrete contexts, respectively. Then, the cross-section distribution of the ecological indicator at time $\mathrm{t}+1$ can be expressed as:

$F_{\mathrm{t}+1}=\mathrm{Q}_{\mathrm{rxr}} \cdot \mathrm{F}_{\mathrm{t}}$,

where $Q_{r x r}$ is a transition probability matrix from one state to another, assuming a countable state space

$E=e_{1}, e_{2}, \ldots ., e_{r}$.

for the analyzed variable. The discretization of the observations' space in which the variables may take values in $r$ states $e_{i}, i=1, \ldots, r$

\footnotetext{
1 The interested reader can gain greater familiarity with some of the concepts introduced here in Quah (1996), among other contributions by the same author.
}

allows intra-distribution mobility to be interpreted straightforwardly. Cell $p_{i j}$ in $Q_{r} \times r$ matrix shows the probability that a country initially affiliated to state $i$ transits during the period or periods (I) considered to state $\mathrm{j}$. In particular, each $\mathrm{p}_{\mathrm{ij}}$ is defined as:

$\mathrm{p}_{\mathrm{ij}}=\frac{1}{\mathrm{~T}-1}{ }_{\mathrm{t}=1}^{\mathrm{T}-1} \frac{\mathrm{N}_{\mathrm{ij}, \mathrm{t}}}{\mathrm{N}_{\mathrm{i}, \mathrm{t}}}$,

where $T$ is the number of periods in the sample, $N_{i j, t}$ is the number of countries transiting during a period from state $i$ to state $j$ and $\mathrm{N}_{\mathrm{i}, \mathrm{t}}$ is the total number of countries starting the period in state i. In addition, each row in the matrix represents a transition probability vector.

Such vectors help to better understand the analogy with the continuous case: they are equivalent to the density probability defined for each point in $\mathrm{E}$, when cutting the figure at that point by a plane parallel to $\mathrm{t}+\mathrm{l}$.

When computing annual transitions (1-year transitions) through transition probability matrices, the available observations for the total studied years could be divided into different states $E=\left(e_{1}, e_{2}, \ldots, e_{n}\right)$, whose upper limits have been selected in such a way that the initial distribution is uniform. This strategy results in different limits for the states, or classes, according to the different indicators considered. If these transition probability matrices were the identity matrix, distributions would be invariant and, furthermore, no intra-distribution movements would occur. In contrast, if probability concentrates off the main diagonal, then high intradistribution mobility (or churning) would exist.

\section{An application to Mediterranean fisheries}

\subsection{Ecological indicators}

Ecological indicators should be sensitive to changes in ecosystem status through space and time, should be easily measured, understandable, informative and based on accessible data (Shin and Shannon, 2010; Pennino et al., 2011). Following these criteria, we have selected three indicators to provide an example on how to apply our methodology: the Marine Trophic Index (MTI), the Fishing in Balance Index (FiB), and the Expansion Factor (EF).

The Marine Trophic Index (MTI) was developed based on the assumption that a decline of the mean trophic level of fisheries catches is generally due to a fishery-induced reduction of the biomass and hence reduced biodiversity of vulnerable predators (Pauly et al., 1998). This index tracks changes in Trophic Levels (hereafter TL) and is calculated from a combination of fisheries landings and TL (higher that 3.25) for the fish species landed. It is computed, for each year $k$ as:

$M T I_{k}=T_{i} T L_{j} \cdot\left(Y_{i k}\right) / \underset{i}{Y_{i k}}$

where $Y_{i k}$ refers to the reported catches of all species $i$ in year $k$ with Trophic Level $T L_{j}$.

Changes in this index could provide useful indications of changes in the abundance and landings of high TL species, which are usually the target fishery species (Vivekanandan et al., 2005; see also Christensen, 2015 and Shannon et al., 2014 for discussions on applicability and limitations of trophic-level based indicators).

The Fishing in Balance Index (FiB) tracks the evolution of catches due to changes in targeting different TL organisms in the ecosystem. Pauly et al. (2000) predicted that a fall of one TL at which a fishery operates would lead to a 10 -fold increase in potential catches because usually the average efficiency of energy transfer is $10 \%$ between TL (Pauly and Christensen, 1995). To study this 


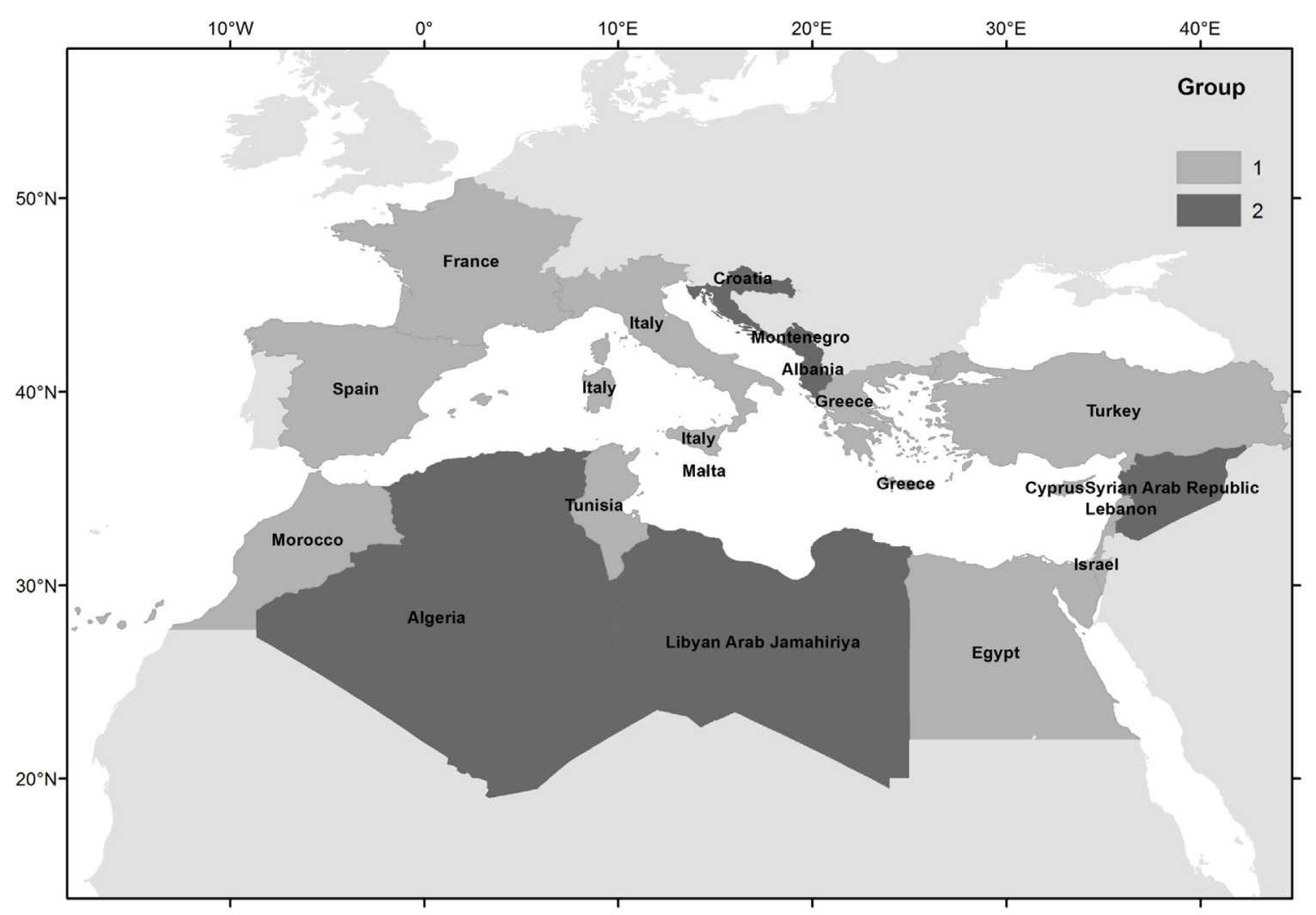

Fig.1. Map of the study area and fishing countries. Countries are divided in the two Gross Domestic Product (GDP) per capita groups, significant at the 95\%level ( $p<0.05)$, obtained with the Cluster Analysis.

effect Christensen (2000) and Pauly et al. (2000) introduced the Fishing-in-Balance (FiB) index as follows:

$\mathrm{FiB}_{\mathrm{k}}=\log \mathrm{Y}_{\mathrm{k}} \cdot \frac{1}{\mathrm{TE}}^{\mathrm{mT \textrm {q } _ { k }}}-\log \mathrm{Y}_{0} \cdot \frac{1}{\mathrm{TE}}^{\mathrm{mTL}_{0}}$,

where $\mathrm{Y}$ corresponds to landings in year $\mathrm{k}, \mathrm{mTL} c$ is the mean TL of the landings in year $k$, TEis the transfer efficiency (here set at 0.1 following Pauly et al., 2000), and 0 refers to any year used as a baseline to standardize the index (Pauly et al., 2000; Christensen, 2000). The FiB index has the property of increasing $(\mathrm{FiB}>0)$ if catches increase faster than would be predicted by TL declines, and of decreasing $(\mathrm{FiB}<0)$ if an increase in catches fails to compensate for a decrease in TL.This is due to the fact that, in the absence of geographic expansion or contraction, and with an ecosystem that has maintained its structural integrity, moving down the food web should result in increased catches (with the converse being true in the event of an increase in $\mathrm{TL}$ ), with the $\mathrm{FiB}$ index remaining constant $(\mathrm{FiB}=0)$.

The Expansion factor (EF) was conceived as an indicator to correct some of the limitations of the previous trophic-based indicators. Viewed jointly, the MTI and FiB illustrate changes in the average $T L$ of catches over time and provide an indication of geographic expansion or contraction over the fishing region. However, it is difficult to evaluate simultaneously the joint message of two indicators representing different aspects of a process (see, e.g., Branch et al., 2010). Therefore, in order to correct the MTI for situations where geographic expansion really occurs (thus fishing is expanding to newer fishing grounds), Kleisner et al. (2014) introduced the expansion factor. This index represents the geographic expansion of a particular fishery trough time and provides further information to contextualize the dynamics of MTI and FiB indexes. Specifically, EFis represented by the potential catch $p Y_{k}$ that reflects the expected value of the maximum potential catch that a fishing fleet should be able to extract from a single fishing region, given the transfer efficiency (TE). The expectation is evaluated over the probability distribution of initial trophic levels as:

$\mathrm{pY}_{\mathrm{k}}=\quad \mathrm{p \textrm {F } _ { \mathrm { j } }} \cdot \operatorname{Pr} \mathrm{TL}_{\mathrm{j}}$,

where $\operatorname{Pr}\left(T L_{j}\right)$ is the probability that the $M T I$ is equal to the initial trophic level $\mathrm{TL}_{j}$ (Kleisner et al., 2014).

\subsection{Data and standardizations}

The ecological indicators of 18 Mediterranean countries were extracted from the Sea Around Us database (www.seaaroundus. org) from 1950 to 2010. The original dataset consists of reconstructed nominal catches and does not include discards, by-catch and illegal, unreported and unregulated (IUU) catches (Pauly and Zeller, 2015).

Mediterranean fisheries vary greatly from country to country. In order to take into account these differences and to avoid influences on the analysis, before applying our techniques, ecological indicators were standardized using a conditioning approach. Specifically, each ecological indicator was standardized relative to the yearly mean of countries grouped according to their Gross Domestic Product (GDP) per capita. The GDP data were obtained from official statistics (United Nations Data, http://data.un.org) for the 1970-2010 period. In order to obtain the statistically different groups in terms of GDP per capita, a Cluster Analysis (CA) was performed on a Euclidean similarity matrix with the Ward method. Ward's method uses an analysis of variance to evaluate the distances between clusters, attempting to minimize the total within-cluster variance. This makes it especially useful to find compact clusters, which is essential for the identification of groups showing a significant degree of association (Shimodaira, 2002). In addition, it is possible to assessfor each cluster a measure 
$1950-1965$

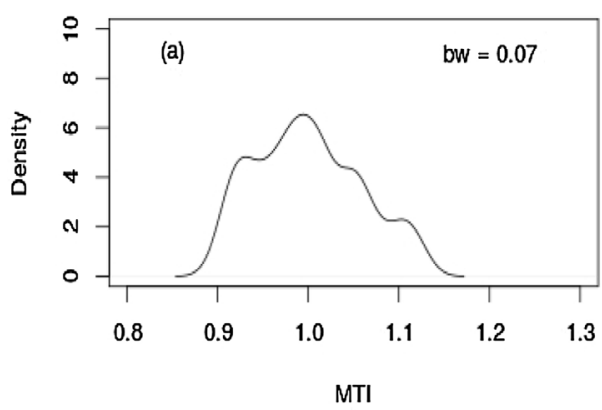

1982-1995

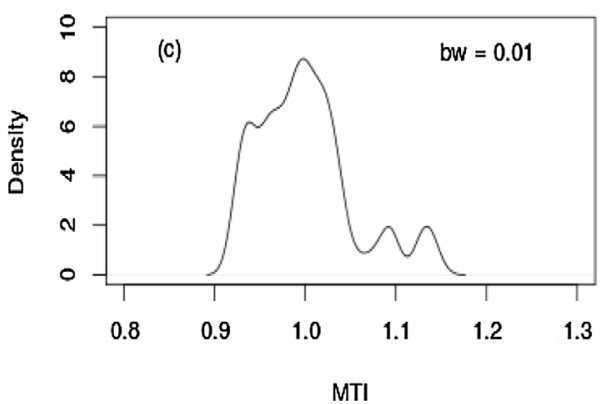

1966-1981

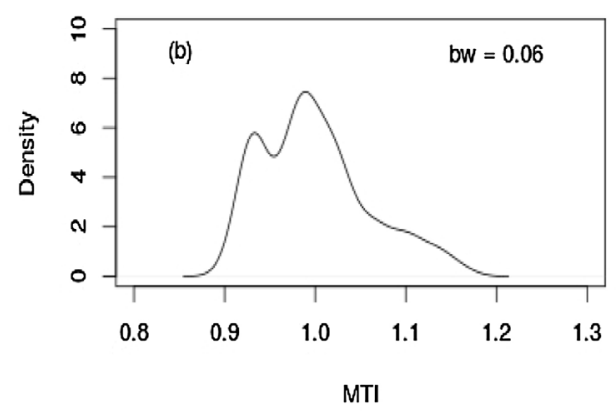

$1996-2010$

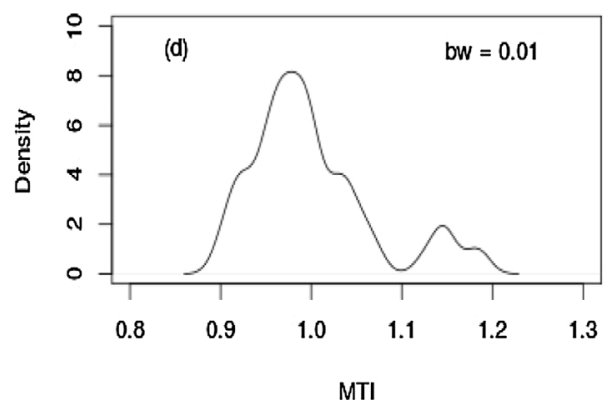

Fig.2. Gaussian kernel smoothing of the Mean trophic Index between 1950 and 1965 (a);1966-1981 (b) $1982-1996$ (c) and 1996-2010 (d). The bandwidth of each density is indicated in the upper right side of the plot (bw).

of uncertainty, the approximate unbiased p-values (AU p-values), and evaluate their significativity, with the bootstrap probability $p$ values (Shimodaira, 2004). The CA analyses were carried out using "pvclust" package in R software (Suzuki and Shimodaira, 2006).

Following this method, results revealed the existence of two different assemblages, significant at least at the 95\% confidence interval $(p<0.05)$, for the Mediterranean countries. Particularly, Israel, Egypt, Lebanon, Turkey, Morocco, Malta, Tunisia, France, Italy, Greece, Cyprus and Spain form a group (Group I), and Croatia, Montenegro, Albania, Algeria, Libya and Syria form a second group (Group II) (Fig. 1).

This procedure has several advantages such as, for instance, avoiding the influence of particular shocks which could affect the indicators, since each ecological indicator could show a tendency either to increase or to decrease. It also enables us to partly offset the distorting effects of outlying observations. In addition, the interpretation is meaningful: values that get close to the indicator average would be interpreted as a convergence to the mean value of all the countries. If relatively richer countries have accessto more advanced fishing technologies than relatively poorer countries, it could result in more homogeneous ecological indicators for countries with similar technologies, and more heterogeneous indicators for countries whose technologies differ.

In addition, we analyzed our results using information for groups of years instead of single years to achieve a more global view of the results while simultaneously maintaining enough level of detail. To do so, we selected four-year intervals (1950-1965, 1966-1981, 1982-1995, 1996-2010) to assess the nonparametric estimation of the density functions.

\section{Convergence of mediterranean fisheries}

\subsection{The marine trophic index}

Fig. 2 shows the time evolution of the distribution of the Marine Trophic Index (MTI) for the different periods selected considering a
Gaussian kernel smoothing approach. Results show that the trend of the MTI is convergent from the begging of the time series. However, in the last two periods of the series (from Fig. 2(c) to Fig. 2(d)), the index shows a bimodal distribution with a bigger peak below MTI average (the significant peak below 1) and another one above the average (the "shoulder"' at about 1.1). These results evidence that fisheries of Mediterranean countries are similar in terms of the MTI, but in the last years a group of countries shows a more heterogeneous MTI with higher values.

This pattern is consistent with Tsikliras et al. (2015) that found that in the Western Mediterranean the MTI trend is increasing and may be attributed to either a decline in the catches of low trophic level species, or an increase in the catches of high trophic level species. This could be a signal of a situation of fishing-up the marine food webs (Stergiou and Tsikliras, 2011; Van Beveren et al., 2014). The trend of the MTI is further explored via transition probability matrices (Table 1).

All the diagonal entry averages are high, showing persistence patterns between countries. Specifically, the average was 0.77 , which means that inter-annual mobility is not very high, at least compared to 61-year transitions.

Finally, the third step of our approach is to analyze the explicit distribution dynamics focuses on the ergodic distribution, corresponding to the stationary state, which informs about the probability of a given country ending up in a certain state of MTI. It is important to bear in mind that this distribution would only be achievable under current trends.

In particular, results from the MTI index show that the probability mass corresponding to the ergodic distribution will be more evenly distributed, suggesting that the differences within the groups of countries considered will persist over the time. However, the majority of the countries will be concentrated in lower levels of the MTI (States $e_{1}$ and $e_{2}$ ) (see Table 1). Such persistence in the lower limits highlights a trend of the increasing prevalence of low trophic level species in the catch over high trophic level species in 
Table1

Transition probability matrix and ergodic distribution of Mean trophic Index (1-year transition).

\begin{tabular}{lllll}
\hline & Statee $_{1}=\mathbf{0 . 9 5}$ & Statee $_{2}=0.98$ & Statee $_{4}=1.00$ & Statee $_{4}=1.05$ \\
$(217)$ & $\mathbf{0 . 8 4}$ & 0.16 & 0.00 & 0.00 \\
$(214)$ & 0.15 & $\mathbf{0 . 6 7}$ & 0.15 & 0.02 \\
$(216)$ & 0.00 & 0.16 & $\mathbf{0 . 7 0}$ & 0.00 \\
$(217)$ & 0.00 & 0.02 & 0.12 & 0.00 \\
$(216)$ & 0.00 & 0.00 & 0.01 & 0.00 \\
Ergodic distribution & $\mathbf{0 . 2 1}$ & $\mathbf{0 . 2 1}$ & $\mathbf{0 . 2 0}$ & 0.08 \\
\end{tabular}

Bold values represent the diagonal entry averages and the final ergodic distribution for each state.

Table2

Transition probability matrix and ergodic distribution of Fishing in balance (1-year transition)

\begin{tabular}{lllll}
\hline & Statee $_{1}=0.09$ & Statee $_{2}=0.58$ & Statee $_{4}=1.15$ & Statee $_{4}=2.01$ \\
\hline$(217)$ & $\mathbf{0 . 7 0}$ & 0.15 & 0.03 & 0.03 \\
$(209)$ & 0.15 & $\mathbf{0 . 6 1}$ & 0.21 & 0.03 \\
$(210)$ & 0.02 & 0.19 & $\mathbf{0 . 5 9}$ & 0.18 \\
$(209)$ & 0.03 & 0.02 & 0.17 & 0.01 \\
$(215)$ & 0.08 & 0.04 & 0.02 & 0.03 \\
Ergodic distribution & $\mathbf{0 . 1 8}$ & $\mathbf{0 . 2 0}$ & $\mathbf{0 . 2 1}$ & 0.15 \\
\end{tabular}

Bold values represent the diagonal entry averages and the final ergodic distribution for each state.

Table3

Transition probability matrix and ergodic distribution of Expansion factor (1-year transition).

\begin{tabular}{lllll}
\hline & Statee $_{1}=0.53$ & Statee $_{2}=0.74$ & Statee $_{4}=0.98$ & Statee $_{4}=1.41$ \\
\hline$(214)$ & $\mathbf{0 . 8 1}$ & 0.15 & 0.01 & 0.02 \\
$(215)$ & 0.16 & $\mathbf{0 . 6 0}$ & 0.19 & 0.03 \\
$(214)$ & 0.03 & 0.20 & $\mathbf{0 . 5 8}$ & 0.17 \\
$(223)$ & 0.02 & 0.04 & 0.21 & 0.02 \\
$(214)$ & 0.00 & 0.01 & 0.02 & 0.02 \\
Ergodic distribution & $\mathbf{0 . 2 3}$ & $\mathbf{0 . 2 1}$ & $\mathbf{0 . 2 0}$ & 0.17 \\
\end{tabular}

Bold values represent the diagonal entry averages and the final ergodic distribution for each state.

the long-run, indicating a lack of sustainability of the fisheries in the marine ecosystem of the Mediterranean Sea.

\subsection{The fishing in balance index}

The results for the Fishing in Balance Index (FiB) show a trend towards convergence. Indeed, while in the first two periods (Fig. 3(a) and (b)) probability mass were spread across a wider range, in more recent years the probability mass is more increasingly concentrated on the average value (Fig. 3(c) and (d)). This tendency implies that the behavior of the different countries tends to become gradually more similar in terms of FiB.

Again, as it occurred with the MTI, all the diagonal entries are high with an average of 0.65 , implying that no intra-distribution movements are occurring. The ergodic distributions show that the probability mass is distributed in FiBstates higher than 0 (Table 2), thus the reported catches are higher than what should be compatible with the MTI for that year, and the transfer efficiency.

FiB values higher than 0 could indicate an expansion of the fishing activities. This expansion could be both, in terms of geographically extension, and/or in terms of exploitation of stocks that were previously unexploited or lightly exploited. This fishery expansion has been previously documented in the western Mediterranean Sea (Coll et al., 2014; Gorelli et al., 2016) and it is probably a consequence of direct government support to the fishing sector aswell as the implementation of technological advances. The modernization of small and large-scale fishing fleets (i.e. larger boats, of higher tonnage and engine horsepower, improved fishing gear, the use of high-technology equipment) is leading to the expansion of fishing in areas previously inaccessible to fishing vessels because of strong winds and in deep water areas.

\subsection{The expansion factor}

The Expansion Factor (EF)time evolution (Fig. 4) shows that this index is moving towards adivergent pattern. In the first two periods of the series (Fig. 4(a) and (b)), the index shows more concentrated probability mass around the average, while in the last two periods of the series (Fig. 4(c) and (d)), the probabilities become more spread and with a group of countries with higher EFvalues.

This tendency could highlight that a group of countries have a geographic expansion higher than the average. Relatively richer countries have access to more advanced fishing technologies than relatively poorer countries, and can expand their fishing grounds. This EFtrends is similar to the MTI pattern and revels that the higher MTI values likely correspond to new fish stocks of high trophic level that were not exploited in the previous years.

As for the others two indices, the Expansion Factor shows no higher no intra-distribution movements (average of 0.67) and thus countries are persistent in their positions (Table 3). However, in the long-run countries will be concentrated in the first two lower states of the EFindex. i.e. the geographic expansion will be lower over the time.

\section{Summary and conclusions}

We present a three-step methodology that illustrates how the distribution of a particular indicator evolves over time, whether indicators converge or not in similar behaviors, and what would be 
$1950-1965$

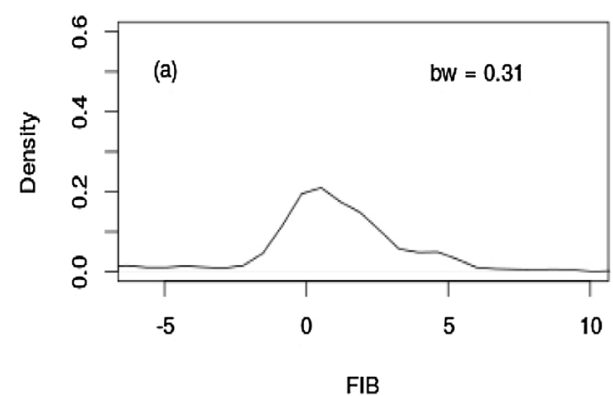

1982-1995

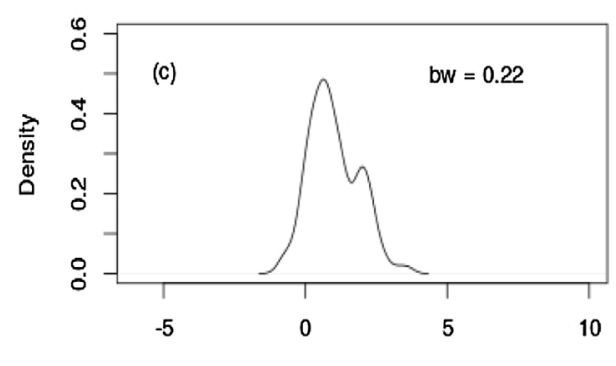

FIB
$1966-1981$

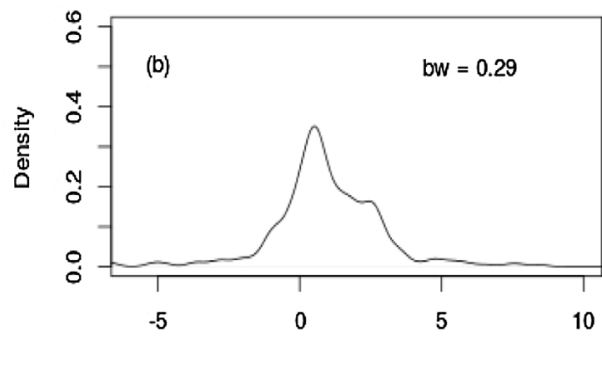

FIB

1996-2010

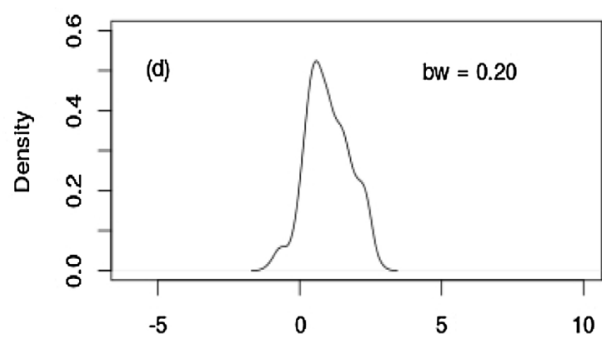

FIB

Fig.3. Gaussian kernel smoothing of the Fishing in Balance between 1950 and 1965 (a);1966-1981 (b) $1982-1996$ (c) and 1996-2010 (d). The bandwidth of each density is indicated in the upper right side of the plot (bw).

$1950-1965$

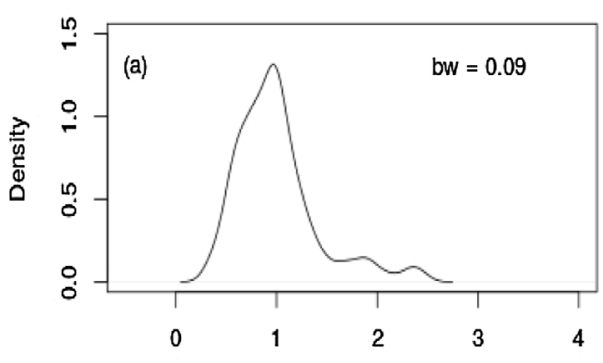

EF

1982-1995

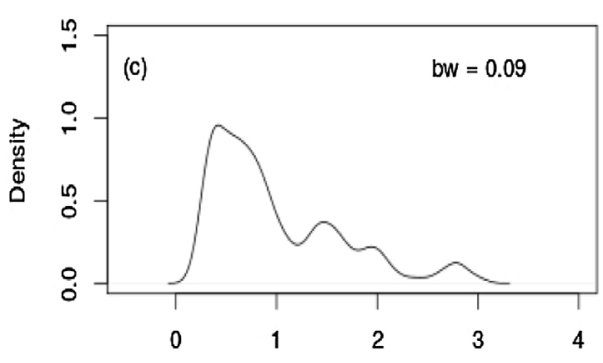

EF
$1966-1981$

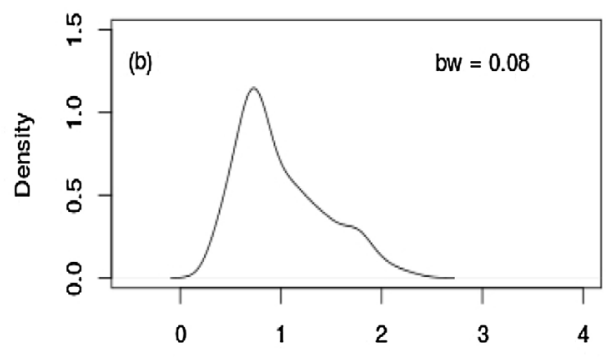

$\mathrm{EF}$

$1996-2010$

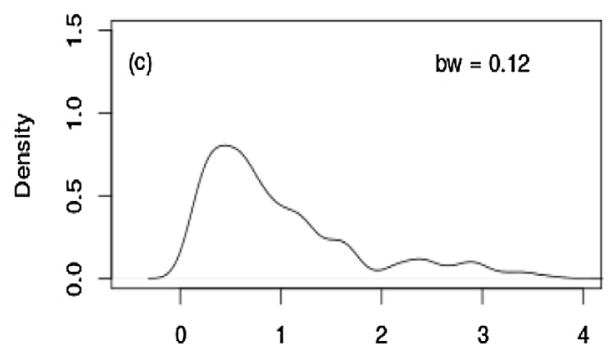

$\mathrm{EF}$

Fig.4. Gaussian kernel smoothing of the Expansion Factor between 1950 and 1965 (a);1966-1981 (b) 1982-1996 (c) and 1996-2010 (d). The bandwidth of each density is indicated in the upper right side of the plot (bw).

their trend in the long-term. This type of methodology is widely used in economic studies, but as far we know has never been applied in Ecology before. However, we illustrate that its application in Ecology can be relevant. The potential applications are wide to different indicators and ecosystems, especially in data poor sit- uations in which it is difficult to use more sophisticated models. This could particularly important in developing countries in which there is still no structure and organized systems to collect data but the capacity to exploit resources is growing exponentially. Marine resources in the Mediterranean Sea are already over-exploited in 
many developed countries (e.g., Colloca et al., 2013) and our study highlights that signals of the beginning of the degradation of marine ecosystems are recognizable and identifiable in some developing countries. Negative effects/symptoms in an over-exploited ecosystem can be identified, prevented and cushioned other ecosystems before they appear or they get higher.

This methodology allows including in the analyses external factors that could influence the studied phenomena using a conditioned approach, as the GDP per capita factor in the case of the Mediterranean fisheries. The approach can also be expanded using other conditioning factors and more indicators, while exploring differences between patterns in others groups of years.

For this specific casestudy, the use of the official landings may be a limitation as this data does not account for discards, by-catch and illegal, unreported and unregulated (IUU) catches. Also, the interpretation of ecological indicators is somehow subjective because we lack reference points or limit values with which to unambiguously assess the status of marine ecosystems (Shin and Shannon, 2010) and we use reference directions assuming a linear relationship between the evolution of the indicator and the degradation of the ecosystem. Despite these limitations, this complementary nonparametric approach provides a novel way to jointly analyze ecological indicators. We assesschanges in fisheries exploitation by different countries and highlight an early warning signal of changes in Mediterranean marine ecosystems. This study represents a new standpoint from which to explore fisheries exploitation and what might be the probable (under current trends) long-term integrity of the ecosystem.

\section{Acknowledgements}

David Conesa thanks the Ministerio de Educación y Ciencia (the Spanish Ministry of Education and Science) via research grants MTM2010-19528, MTM2013-42323 (jointly financed with the European Regional Development Fund). Marta Coll was partially funded by the European Commission through the Marie Curie Career Integration Grant Fellowships - PCIG10-GA-2011-303534 to the BIOWEB project. Authors do not have any conflict of interest to declare.

\section{References}

Akpalu, W., 2009. Economics of biodiversity and sustainable fisheries management. Ecol. Econ. 68, 2729-2733.

Barro, R.J.Sala-i-Martin, X., 1992. Convergence. J.Polit. Econ. 100, 223-251.

Branch, T.A., Watson, R., Fulton, E.A., Jennings, S., McGilliard, C.R.,Pablico, G.T., Richard, D., Tracey, S.R.,2010. The trophic fingerprint of marine fisheries. Nature 468 (7322), 431-435.

Christensen, V., 2000. Indicators for marine ecosystems affected by fisheries. Mar. Freshwater Res. 51, 447-450.

Christensen, V., 2015. Fishing down through the food web. Fisheries 40 (8), 370-372.

Coll, M., Piroddi, C.,Steenbeek, J.,Kaschner, K., Ben Rais Lasram, F.,Aguzzi, J.,et al., 2010. The biodiversity of the Mediterranean Sea: estimates, patterns, and threats. PLoSOne 5 (8), e11842.

Coll, M., Carreras, M., Cornax, M.J., Massutí, E., Morote, E., Pastor, X., Quetglas, A. Saez, R., Silva, L., Sobrino, I., Torres, M.A., Tuleda, S., Harper, S.,Zeller, D., Pauly, D., 2014. Closer to reality: reconstructing total removals in mixed fisheries from Southern Europe. Fish. Res.154, 179-194.

Colloca, F., Cardinale, M., Maynou, F., Giannoulaki, M., Scarcella, G., Jenko, K., Bellido, J.M.,Fiorentino, F.,2013. Rebuilding Mediterranean fisheries: a new paradigm for ecological sustainability. Fish Fish. 14 (1), 89-109.

Cotter, J.,Petitgas, P., Abella, A., Apostolaki, P., Mesnil, B., Politou, C., Rivoirard, J., Rochet, M.J., Spedicato, M.T., Trenkel, V.M., et al., 2009. Towards an ecosystem approach to fisheries management (EAFM) when trawl surveys provide the main source of information. Aquat. Living Resour. 22 (2), 243-254.

Cury, P.M., Shannon, L.J.,Roux, J.P.,Daskalov, G.M., Jarre, A., Moloney, C.L.,Pauly, D. 2005. Trophodynamic indicators for an ecosystem approach to fisheries. ICESJ. Mar. Sci. 62 (3), 430-442.

Dale, V., Beyeler, S.,2001. Challenges in the development and use of ecological indicators. Ecol. Indic. 1, 3-10.
Doyen, L., Thebaud, O., Bene, C., Martinet, V., Gourguet, S.,Bertignac, M., Fifas, S., Blanchard, F., 2012. A stochastic viability ap- proach to ecosystem-based fisheries management. Ecol. Econ. 75, 32-42.

Fulton, E.A., Fuller, M., Smith, A.D.M., Punt, A.E.,2005. Ecological Indicators of the Ecosystem Effects of Fishing: Final Report. Australian Fisheries Management Authority Report, R99/1546. pp. 239.

Geweke, J.,Marshall, R.C.,Zarkin, G.A., 1986. Mobility indices in continuous time Markov chains. Econometrica 54 (6), 1407-1423.

Gonzalez-Riancho, P., Sano, M., Medina, R., Garcıa-Aguilar, O., Areizaga, J.,2009. A contribution to the implementation of ICZM in the Mediterranean developing countries. Ocean Coast. Manage. 52, 545-558.

Gorelli, G., Sardà, F., Company, J.B.,2016. Fishing effort increase and resource status of the deep-sea red shrimp Aristeus antennatus (Risso 1816) in the Northwest Mediterranean Seasince the 1950. Rev. Fish. Sci. Aquac. 24 (2), 192-202.

Hollingworth, C., et al., 2000. Ecosystem effects of fishing: proceedings of an ICES/SCORsymposium held in Montpellier, France 16-19 March 1999. ICESJ. Mar. Sci. 57, 465-791.

Jones, M., Marron, J.,Sheather, S.,1996. A brief survey of bandwidth selection for density estimation. J.Am. Stat. Assoc. 91, 401-407.

Kleisner, K., Mansour, H., Pauly, D., 2014. Region-based MTI: resolving geographic expansion in the marine trophic index. Mar. Ecol. Prog. Ser. 512, 185-199.

Mitsch, W.J., Wang, N., Zhang, L., Deal, R., Wu, X., Zuwerink, A., 2005. Using ecological indicators in a whole-ecosystem wetland experiment. In: Handbook of Ecological Indicators for Assessment of Ecosystem Health. Taylor \& Francis, Boca Raton, FL, USA, pp. 213-237.

Niemi, G.J.,McDonald, M.E., 2004. Application of ecological indicators. Annu. Rev. Ecol. Evol. Syst., 89-111.

Pauly, D., Watson, R., 2005. Background and interpretation of the marine trophic index as a measure of biodiversity. Philos. Trans. R Soc. B: Biol. Sci. 360, 415-423.

Pauly, D., Zeller, D. (Eds.), 2015. seaaroundus.org).

Pauly, D., Zeller, D., 2016. Catch reconstructions reveal that global marine fisheries catches are higher than reported and declining. Nat. Com. 7

Pauly, D., Christensen, V., Dalsgaard, J.,Froese, R., Torres Jr, F., 1998. Fishing down marine food webs. Science 279, 860-863.

Pauly, D., Christensen, V., Walters, C., 2000. Ecopath, ecosim, and ecospace as tools for evaluating ecosystem impact of fisheries. ICESJ.Mar. Sci. 57, 697-706.

Pennino, M.G., Conesa, D., López-Quílez, A., Bellido, J.M.,2011. Trophic indicators to measure the impact of fishing on an exploited ecosystem. Anim. Biodivers. Conserv. 34 (1), 123-131.

Pikitch, E.K., Santora, C., Babcock, E.A., Bakun, A., Bonfil, R., Conover, D.O., Dayton, P., Doukakis, P., Fluharty, D., Heneman, B., Houde, E.D., Link, J.,Livingston, P.A., Mangel, M., McAllister, M.K., Pope, J.,Sainsbury, K.J.,2004. Ecosystem-based fishery management. Science 305 (5682), 346-347.

Quah, D.T., 1993a. Empirical cross-section dynamics in economic growth. Eur. Econ. Rev. 37, 426-434.

Quah, D.T., 1993b. Galton's fallacy and tests of the convergence hy- pothesis. Scand. J.Econ. 95, 427-443.

Quah, D.T., 1996. Empirics for economic growth and convergence. Eur. Econ. Rev. 40, 1353-1375.

Quah, D.T., 1997. Empirics for growth and distribution: stratification, polarization and convergence clubs. J.Econ. Growth 2 (1), 27-59.

RDevelopment Core Team, 2016. R: A Language and Environment for Statistical Computing. R Foundation for Statistical Computing, Vienna, Austria, URL: http://www.R-project.org/.

Rosenberg, A.A., Fogarty, M.J., Cooper, A.B., Dickey-Collas, M., Fulton, E.A., Gutiérrez, N.L., Hyde, K.J.W., Kleisner, K.M., Kristiansen, T., Longo, C., Minte-Vera, C. Minto, C., Mosqueira, I., Chato Osio, G., Ovando, D., Selig, E.R., Thorson, J.T.,Ye, Y., 2014. Developing new approaches to global stock status assessment and fishery production potential of the seas. In: FAOFisheries and Aquaculture Circular No. 1086, Rome, FAO, 175 pp.

Scott, D.W., 1992. Multivariate Density Estimation: Theory, Practice, and Visualization. Wiley, New York.

Shannon, L., Coll, M., Bundy, A., Gascuel, D., Heymans, J.J.Kleisner, K., et al., 2014. Trophic level-based indicators to track fishing impacts across marine ecosystems. Mar. Ecol. Prog. Ser. 512, 115-140.

Sheather, S., Jones, M., 1991. A reliable data-based bandwidth selection method for kernel density estimation. J.Royal Stat. Soc. Series B (Methodological) 53, 683-690.

Shimodaira, H., 2002. An approximately unbiased test of phylogenetic tree selection. Syst. Biol. 51 (3), 492-508.

Shimodaira, H., 2004. Approximately unbiased tests of regions using multistep-multiscale bootstrap resampling. Ann. Stat. 32 (6), 2616-2641.

Shin, Y.J.,Shannon, L.J.,2010. Using indicators for evaluating, comparing, and communicating the ecological status of exploited marine ecosystems. ICESJ. Mar. Sci. 67, 686-691.

Silverman, B., 1986. Density Estimation for Statistics and Data Analysis, Volume 1. Chapman and Hall, London.

Stergiou, K.I., Tsikliras, A.C.,2011. Fishing-down: fishing-through and fishing-up: fundamental process versus technical details. Mar. Ecol. Prog. Ser. 441, 230-295.

Suzuki, R., Shimodaira, H., 2006. Pvclust: an R package for assessing the uncertainty in hierarchical clustering. BMC 22 (12), 1540-1542.

Tortosa-Ausina, E., 2002. Exploring efficiency differences over time in the Spanish banking industry. Eur. J.Oper. Res. 139 (3), 643-664. 
Tsikliras, A.C., Dinouli, A., Tsiros, V.Z., Tsalkou, E., 2015. The Mediterranean and Black Seafisheries at risk from overexploitation. PLoSOne 10 (3), e0121188. Turnhout, E., Hisschemöller, M., Eijsackers, H., 2007. Ecological indicators: between the two fires of science and policy. Ecol. Indic. 7 (2), 215-228.

Van Beveren, E., Bonhommeau, S., Fromentin, J.-M., Bigot, J.-L., Bourdeix, J.-H., Brosset, P., et al., 2014. Rapid changes in growth, condition, size and age of small pelagic fish in the Mediterranean. Mar. Biol. 161, 1809-1822.
Vivekanandan, E., Srinath, M., Kuriakose, S.,2005. Fishing the marine food web along the indian coast. Fish. Res.72, 241-252.

Wand, M., 2015. KernSmooth, 2. R package version, pp. 15-23.

Worm, B., Barbier, E.B.,Beaumont, N., Duffy, J.E.,Folke, C., Halpern, B.S.,Jackson, J.B.C.Lotze, H.K., Micheli, F., Palumbi, S.R.,Sala, E., Selkoe, K.A., Stachowicz, J.J., Watson, R., 2006. Impacts of biodiversity loss on ocean ecosystem services. Science 314, 787-790.

Worm, B., Branch, T.A., 2012. The future of fish. Trends Ecol. Evol. 27 (11), 594-599. 